\title{
CENÁRIOS HISTÓRICOS DA OFERTA DE EDUCAÇÃO PROFISSIONAL PELO BRASIL PROFISSIONALIZADO NAS ESCOLAS ESTADUAIS DE MOSSORÓ/RN
}

\author{
Francisca Natália Silva ${ }^{1}$; Erika Roberta Silva de Lima ${ }^{1}$; Lenina Lopes Soares Silva ${ }^{2}$ \\ ${ }^{1}$ Universidade do Estado do Rio Grande do Norte; ${ }^{2}$ Instituto Federal de Educação, Ciência e \\ Tecnologia do Rio Grande do Norte \\ DOI: 10.15628/rbept.2018.7276
}

Artigo submetido em maio/2018 e aceito em junho/2018

\begin{abstract}
RESUMO
Objetiva-se discutir os aspectos históricos que acompanham a implementação da Educação Profissional nas escolas estaduais da rede de ensino de Mossoró/RN, com ênfase nas políticas implementadas na Escola Estadual Jerônimo Rosado e na Estadual Professor Abel Freire Coelho. Adotou-se como percurso metodológico a pesquisa bibliográfica e empírica. Na revisão bibliográfica dialogou-se, sobre as concepções de Estado e suas transformações no contexto da sociedade moderna e acerca dos fundamentos utilizados como justificativa para as reformas e organização do Ensino Médio e da Educação Profissional. Na pesquisa empírica utilizamos entrevistas semiestruturadas com dois representantes de gestão que atuavam no período em que foi feita a adesão à proposta do Programa Brasil Profissionalizado pelas escolas e dois gestores atuavam na implementação da política de 2014 a 2016. Consideramos que, analisando-se os aspectos históricos que permeiam as políticas implementadas para articulação do Ensino Médio à Educação Profissional nas escolas campo de pesquisa é possível perceber como essas se justificam pelas necessidades de minimizar as desigualdades sociais dos sujeitos que frequentam essas escolas.
\end{abstract}

Palavras-Chave: Ensino Médio. Educação Profissional. História da Educação Profissional no Rio Grande do Norte.

\section{HISTORICAL SCENARIOS OF PROFESSIONAL EDUCATION OFFERED BY BRAZIL PROFESSIONAL IN THE STATE SCHOOLS OF MOSSORÓ / RN}

\begin{abstract}
The objective is to discuss the historical aspects that accompany the implementation of Professional Education in the state schools of the Mossoró / RN educational network, with emphasis on the policies implemented at the Jerônimo Rosado State School and the State Professor Abel Freire Coelho. The bibliographic and empirical research was adopted as methodological course. In the bibliographical review, there was a dialogue about the conceptions of the State and its transformations in the context of modern society and about the foundations used as justification for the reforms and organization of Secondary Education and Professional Education. In the empirical research, we used semi-structured interviews with two management representatives who were in the period when the proposal for the Brazil Program was implemented by the schools and two managers were involved in the implementation of the policy from 2014 to 2016. We consider that, by analyzing the aspects that permeate the policies implemented to articulate the High School to Vocational Education in the schools field of research, it is possible to perceive how these are justified by the needs of minimizing the social inequalities of the subjects that attend these schools.
\end{abstract}

Keywords: Secondary Education. Professional Education. History of Professional Education in Rio Grande do Norte. 


\section{INTRODUÇÃO}

Ao contextualizar a implementação de uma política educacional é indispensável analisar as múltiplas dimensões que cercaram sua formação históricosocial e sua consolidação e desenvolvimento. Com base nessa perspectiva de análise de implementação não é possível estudar as instituições escolares como entidades deslocadas do contexto de produção social dos indivíduos para compreendê-las como produtos de embates, disputas e determinações da sociedade reguladas por um Estado cuja formação capitalista vem ocorrendo de forma excludente baseada na exploração do trabalho e na educação dual.

Como resultado, as escolas apresentam-se como espaços que detêm fontes e informações fundamentais para a formulação de pesquisas, que permitem a compreensão de elementos relacionados ao processo de ensino, trabalho, ciência, cultura, tecnologia e arte. (BRAZIL; FURTADO, 2010). São espaços nos quais são possíveis o estudo da implementação de políticas e programas educacionais. Tal investigação é possível mediante discursos de professores, alunos e gestores, bem como pela disposição de documentos institucionais da gestão das escolas.

Neste trabalho, temos como objetivo discutir os aspectos históricos que acompanham a implementação da Educação Profissional nas escolas estaduais da rede de ensino de Mossoró/RN, com ênfase nas políticas implementadas na Escola Estadual Jerônimo Rosado e na Estadual Professor Abel Freire Coelho. A análise de implementação orienta-se pelas seguintes perguntas: quais políticas e programas foram implementados na escola? Dentre as políticas e programas, quais eram destinados à articulação do Ensino Médio à Educação Profissional? Como as políticas e programas são apresentados e selecionados pela escola?

Para realização do objetivo proposto neste trabalho, adotou-se como percurso metodológico a pesquisa bibliográfica e empírica. Na revisão bibliográfica dialogouse, entre outros, com trabalhos de lanni (1971), Carnoy (1988), Santos (1982), Afonso (2001) e Höfling (2001), discutindo as concepções de Estado e suas transformações no contexto da sociedade moderna; Moura (2012), Kuenzer (2009), Santos (2007), Ciavatta e Ramos (2011) e Kuenzer e Grabowski (2006) abordando as reformas e organização do Ensino Médio e da Educação Profissional.

$\mathrm{Na}$ pesquisa empírica, utilizamos entrevistas semiestruturadas com dois representantes de gestão que atuavam no período em que foi feita a adesão à proposta do Programa Brasil Profissionalizado pelas escolas e dois gestores que atuavam na implementação da política de 2014 a 2016. Vale salientar que nas políticas implementadas para articulação do Ensino Médio à Educação Profissional, percebemos que as políticas e programas formulados e implementados para viabilizar essa articulação justificam-se pelas necessidades de minimizar as desigualdades sociais dos sujeitos que frequentam essas escolas.

As discussões deste texto se encontram sistematizados em dois tópicos, além deste introdutório. No tópico, Cenários e influências na oferta da Educação 
Profissional, descreve-se a história das instituições na oferta da educação profissional articulada com o ensino médio nas escolas estaduais. Em seguida, no tópico, Articulação entre ensino médio e educação profissional, os discursos dos gestores contextualizam os processos e ações de articulação implementados nas escolas estaduais de Mossoró/RN. Por fim, nas considerações, traça-se sinalizações para a compreensão das escolas como espaços favoráveis para concentração de políticas públicas que visam minimizar as desigualdades estruturais por serem espaços de construção e reconstrução das relações sociais e políticas.

\section{CENÁRIOS E INFLUÊNCIAS DA OFERTA DE EDUCAÇÃO PROFISSIONAL NAS ESCOLAS DA REDE ESTADUAL DE MOSSORÓ/RN}

O campo da História da Educação passou a ser orientado por abordagens que contemplam nas análises dos fenômenos a dimensão global e local dos acontecimentos. Assim, ganha espaço nas produções acadêmicas as propostas que visam à valorização das peculiaridades locais, sem desconsiderar as dimensões global do fenômeno estudado. Isso possibilita a inserção dos processos históricos como uma dimensão relevante na análise política (TOLEDO; ANDRADE, 2014).

Além disso, ainda tem sua trajetória de consolidação marcada pela imersão de outros objetos de estudos nas pesquisas, sendo possível destacar as pesquisas que adotam como objeto a história das instituições escolares, apontando significativas contribuições para o avanço do conhecimento no que se refere às questões educacionais do passado. (BRAZIL; FURTADO, 2010).

Nesse movimento dialético da construção do conhecimento e registro da história são consideradas nas análises as concepções, posições político-ideológicas e ações que estão relacionadas ao cenário que o fenômeno está atrelado. (CIAVATTA; SILVEIRA, 2010). Portanto, nesse processo as instituições mostram-se como:

Produto da ação humana e são voltadas para atender a necessidades presentes. No caso das instituições escolares, especificamente, é correto dizer que elas surgem para atender a necessidades humanas, pois não é toda e qualquer necessidade que requer uma instituição. (TOLEDO; ANDRADE, 2014, p. 181).

Nesse sentido, não é possível estudar as instituições escolares como entidades deslocadas do contexto de produção social do indivíduo, mas como produto de embates, disputas e determinações exteriores da sociedade, mediado por ações que nelas chegam para execução para atendimento de demandas sociais.

Como resultado, as escolas apresentam-se como espaços que detêm fontes e informações fundamentais para a formulação de pesquisas que permitem a compreensão de elementos relacionados ao processo de ensino, cultura escolar e, por conseguinte, são espaços nos quais se registra a real história da educação (BRAZIL; FURTADO, 2010). Assim sendo, quando o pesquisador se propõe a investigar uma instituição escolar tem que ponderar as múltiplas dimensões que 
cercaram sua implantação, consolidação e desenvolvimento. No caso deste trabalho, discute-se a história da Escola Estadual Jerônimo Rosado e da Escola Estadual Professor Freire Coelho na oferta de Educação Profissional, tendo como ponto de partida a sua criação. As escolas investigadas foram fundadas em cenários políticos e educacionais específicos como são apresentados a seguir, ressaltandose os aspectos históricos.

\subsection{ESCOLA ESTADUAL JERÔNIMO ROSADO}

Após lutas e embates políticos, por meio do Decreto do Governo do Estado no 165/1922 foi fundada a Escola Normal Primária de Mossoró/RN ${ }^{1}$ Inicialmente, fixada no centro da cidade, funcionando no edifício de origem até 1959. Naquele contexto político, as reivindicações para sua criação foram norteadas mediante o argumento da necessidade de criação de instituições que estivessem voltadas para ofertar formação de professores para atender às demandas educacionais de profissionais qualificados nesse Estado ${ }^{2}$. Quando fundada tinha como finalidade a preparação de professores para atuarem nas escolas do interior do RN. Posteriormente, após a mudança da estrutura física a escola passou a ser chamada de Centro Educacional do Magistério Primário de Mossoró $^{3}$. Além dessa nomenclatura, também foi intitulada de Colégio Estadual de Mossoró, Centro Educacional Jerônimo Rosado e, atualmente, Escola Estadual Jerônimo Rosado. (SARMENTO, 2013).

No período de realização desta pesquisa, a escola ofertava o Ensino Fundamental e o Ensino Médio, além da oferta das modalidades de Educação Profissional e Educação de Jovens e Adultos. A Escola atende, em média, 680 alunos entre os turnos matutino e vespertino. Os alunos são oriundos dos bairros próximos e da zona rural. Ressaltamos que, a oferta da Educação Profissional é realizada na instituição pela via de Cursos de Formação Inicial e Continuada (FIC) do Programa Nacional de Acesso ao Ensino Técnico e Emprego (PRONATEC).

\subsection{ESCOLA ESTADUAL PROFESSOR ABEL FREIRE COELHO}

Criada por meio do Ato no 7.681/1979, a Escola Estadual Professor Abel Freire Coelho fica localizada em um bairro periférico urbano da cidade de Mossoró/RN. No plano político, sua fundação aconteceu durante a ditadura civilmilitar (1964-1985). Assim sendo, o país era governado pelos militares que instauravam medidas ditatoriais e repressivas no âmago da sociedade brasileira. (IANNI, 1971). As intervenções militares na política tinham como finalidade a construção e fortalecimento do ideário de sociedade e de Estado coerente com o

\footnotetext{
${ }^{1}$ Criada no mandato do governador Antônio José de Melo e Souza (1920-1923). (SARMENTO, 2013, p. 23).

2 Desse modo, em 1908, tivemos de fato, através do Decreto o 178 de 29 de abril, uma institucionalização do ensino normal no Estado do Rio Grande do Norte. (SARMENTO, 2013).

${ }^{3}$ Passou a funcionar no prédio do Instituto de Educação de Mossoró, localizado à rua Ferreira Itajubá - Praça Dom João Costa, no bairro Santo Antônio. (SARMENTO, 2013, p. 23).
} 
discurso de desenvolvimento do país e, sobretudo, da educação requerida para dar sustentáculo ao projeto de nação almejado, que prezava pela ordem e o progresso, conforme fundamentos positivistas. (GERMANO, 2008).

No que concerne à educação, as ações desse governo eram planejadas mediante a proposição de políticas, medidas, programas e projetos educacionais. Nessa proposição, foi lançada a campanha definida como o dia "D" da educação, coordenada pelo Ministério da Educação em parceria com as secretarias estaduais de educação que adotaram o slogan: "a escola que temos e a escola que queremos." (HOTZ, 2008).

Dentro da Campanha se destacaram as ações para ampliar a oferta da Educação Profissional. Essa tinha respaldo na Reforma da Educação Básica, instituída pela Lei oㅜ 5.692/1971 (Lei da Reforma de Ensino de 1ํ e 2o Graus). Apesar da Lei instituir alterações na organização do $1^{\circ}$ e $2^{\circ}$ Graus, evidenciou-se, durante o processo de implementação, o caráter de profissionalização obrigatória atribuída ao ensino de $2^{\circ}$ Grau que foi ali instituído. (SANTOS, 2007). Tal medida orientava a realização do $2^{\circ}$ Grau voltado para atender às necessidades do mercado de trabalho.

A Lei ganhou reforço por meio da Secretaria Nacional de Educação Tecnológica (SENETE/MEC) para implementação do Programa de Expansão e Melhoria do Ensino Técnico (PROTEC). O Programa contemplava os objetivos de "promover a expansão, melhoria do ensino médio e ajustar a oferta desse nível de ensino às exigências de um mercado de trabalho em processo da expansão." (BRASIL, 1992, p. 58).

Essas medidas e ações se refletiram nas formas de organização da instituição e tipo de formação destinada aos jovens atendidos nessa escola. Quando criada, a escola ofertava o ensino de $2^{\circ}$ Grau por meio dos seguintes cursos: Setor Terciário, Auxiliar Técnico de Eletrônica, Habilitação Básica em Mecânica, Auxiliar Técnico de Edificação, Habilitação Básica em Saúde, Habilitação Básica em Crédito e Finanças, ambos os Cursos categorizados como Formação Profissionalizante Básica, embasados na legislação educacional vigente naquele momento.

Posteriormente, outras políticas e programas de Educação Profissional foram implementados pela instituição, sendo possível acentuar os seguintes: Curso de Técnico em Secretariado, em 2006; Programa Brasil Profissionalizado, em 2009; e Programa Nacional de Acesso ao Ensino Técnico e Emprego (PRONATEC), em 2011.

Atualmente, a escola atende 894 alunos. Além da oferta do Ensino Médio Regular a escola também trabalha com a oferta da modalidade de Educação Profissional, sendo realizada por meio do PRONATEC e do Programa Brasil Profissionalizado. (ESCOLA ESTADUAL PROFESSOR ABEL FREIRE COELHO, 2015). Essas são as principais características acerca do tema em estudo das escolas que se constituem como campo de pesquisa para analisarmos in loco a implementação do Programa Brasil Profissionalizado. 


\section{ARTICULAÇÃO ENTRE ENSINO MÉDIO E EDUCAÇÃO PROFISSIONAL}

As políticas e programas implementados, nos últimos anos, trazem em seus discursos a finalidade de melhoria da oferta do Ensino Médio e da Educação Profissional. Dessas iniciativas resultam a ampliação da oferta por meio de incentivos ao desenvolvimento da Educação Profissional nas escolas públicas estaduais e federais, bem como por meio de acordos de gratuidade com a rede privada e financiamento aos estudantes do Ensino Médio da rede pública. (PACHECO, 2011).

Com as discussões feitas do ponto de vista teórico, buscamos conhecer nos discursos dos gestores das políticas e programas implementados nas escolas estudadas para articulação do Ensino Médio à Educação Profissional, evidências que nos possibilitassem responder às questões: nesse período, quais políticas e programas foram implementados nas escolas? Dentre as políticas e programas, quais eram destinados à articulação do Ensino Médio à Educação Profissional? Como as políticas e programas são apresentados e selecionados pela escola?

Partimos de premissas que nos informam que a implementação de políticas e programas demanda ações e intervenções do Estado na designação do padrão de proteção social para a redistribuição dos bens sociais e econômicos, tendo como finalidade reduzir as desigualdades estruturais. (HÖFLING, 2001). As justificativas para formulação e implementação dessas políticas que buscam minimizar as desigualdades sociais ancoram-se, principalmente, nos argumentos de que a

[...] cobertura educacional insuficiente, evidenciada por baixas taxas de matrícula bruta e líquida e pela histórica dicotomia com a educação profissional, remete a graves problemas e desafios para a democratização do acesso e a permanência com qualidade nesta etapa/modalidade da educação básica para todos. (DOURADO, 2011, p. 08).

Em vista disso, as escolas são representadas como espaços favoráveis para concentração de políticas públicas que visam minimizar as desigualdades estruturais por serem espaços de construção e reconstrução das relações sociais e políticas. Tal fato, é ressaltado nos discursos dos gestores entrevistados ao serem questionados sobre as políticas e programas já implementados nas escolas estudadas, conforme a Figura 16. 
Figura 16 - Quadro das Políticas e Programas implementados (2007-2015)

\begin{tabular}{|c|c|c|}
\hline & Escola Estadual Jerônimo Rosado & $\begin{array}{l}\text { Escola Estadual Professor Abel Freire } \\
\text { Coelho }\end{array}$ \\
\hline 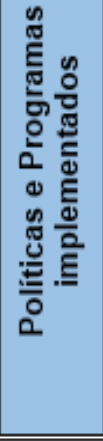 & 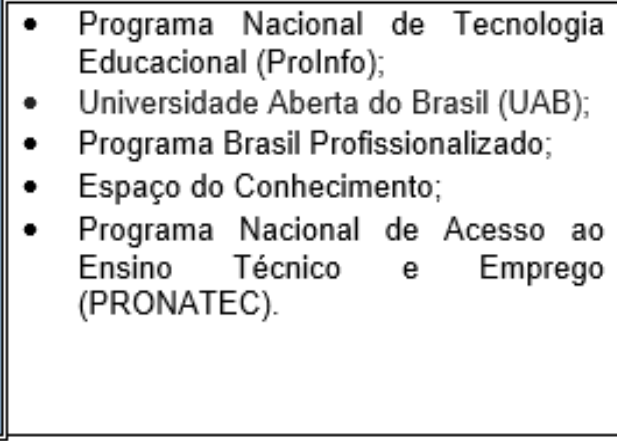 & $\begin{array}{l}\text { - Programa Institucional de Bolsas de } \\
\text { Iniciação à Docência (PIBID); } \\
\text { - Programa Institucional de Bolsas de } \\
\text { Iniciação Científica (PIBIC); } \\
\text { - Espaço do Conhecimento; } \\
\text { - Curso Técnico de Nível Médio Integrado } \\
\text { em Secretariado (Ensino Médio integrado a } \\
\text { Educação Profissional); } \\
\text { - Programa Brasil Profissionalizado; } \\
\text { - Programa Nacional de Acesso ao Ensino } \\
\text { Técnico e Emprego (PRONATEC). }\end{array}$ \\
\hline
\end{tabular}

Fonte: Elaboração da autora com base na análise da entrevista semiestruturada aplicada aos gestores das respectivas escolas.

Em linhas gerais, a Figura 01, apresenta uma diversidade de políticas implementadas no recorte temporal de 2007 a 2015, tendo como eixo central as ações para expandir e melhorar a qualidade da oferta do Ensino Médio e articular o Ensino Médio à Educação Profissional.

No que compete ao favorecimento da expansão e qualidade da oferta do Ensino Médio destacam-se nas vozes dos gestores as seguintes iniciativas:

a) Programa Institucional de Bolsas de Iniciação à Docência (PIBID), que incentiva a valorização do magistério e aprimora o processo de formação de docentes para a Educação Básica;

b) Programa Institucional de Bolsas de Iniciação Científica (PIBIC), que apoia a política de Iniciação Científica desenvolvida nas Instituições de ensino e/ou pesquisa, por meio da concessão de bolsas a estudantes de graduação ligados à pesquisa científica;

c) Espaço do Conhecimento, tendo como objetivo estimular a iniciação científica para alunos do Ensino Médio, por meio da instalação de laboratórios de ciências, matemática e informática nas escolas estaduais;

d) e Programa Nacional de Tecnologia Educacional (PROINFO), criado com a finalidade de promover 0 uso da tecnologia como ferramenta de enriquecimento pedagógico no ensino Fundamental e Médio. (BRASIL, 2007; 2010).

O delineamento desses programas tem como base a expansão e melhoria da qualidade da oferta do Ensino Médio nas escolas públicas. Vale destacar, segundo Dourado e Oliveira (2009), a compreensão da categoria qualidade que fundamentase numa perspectiva polissêmica, pois envolve concepções de mundo, sociedade e educação, sendo respaldadas nos elementos de qualificar, avaliar, precisar a natureza, as propriedades e as particularidades desejáveis de um processo 
educativo que anseie a qualidade social. Orientando-se, portanto, pelas finalidades educativas propostas.

Com base nessa compreensão, as escolas fazem adesão às políticas e programas de articulação entre Ensino Médio e Educação Profissional, tais como: Curso Técnico de Nível Médio Integrado em Secretariado (Ensino Médio integrado a Educação Profissional), Programa Brasil Profissionalizado e PRONATEC.

Assim, por corroborar tal processo, as políticas e os programas governamentais quando relacionados

[...] ao ensino médio, explicitam alguns dos elementos de sua estrutura e as concepções em disputa. $\mathrm{O}$ dualismo estrutural da educação brasileira e o fato de o ensino oferecido a cada grupo social ter um tipo de escola com diferentes condições de modo que nas escolas que atendem os setores populares não garantem uma educação de qualidade, o que tem definido e configurado as políticas públicas no Brasil. (SIMÕES, 2011, p. 112).

Conforme o autor, as políticas e programas são formulados e gestados mediante a busca pela superação do dualismo estrutural do Estado brasileiro. Além disso, visam superar as condições histórias de desigualdades dessa oferta, sendo respaldadas nos discursos de oferta de uma educação de qualidade.

Nas vozes dos gestores da Escola Estadual Jerônimo Rosado foram elencadas as seguintes políticas e programas: Programa Nacional de Tecnologia Educacional (Prolnfo), Espaço do Conhecimento, Universidade Aberta do Brasil (UAB), Programa Brasil Profissionalizado e Programa Nacional de Acesso ao Ensino Técnico e Emprego (PRONATEC).

A adesão a essas iniciativas seria feita com o intuito de agregar mais qualidade ao funcionamento dessa escola pública quando afirma: "[...] ficam [12 DIRED/SEEC] dizendo que os programas vão ajudar a melhorar a escola e no final é tanto programa acontecendo aqui que, às vezes, nem entendemos direito o que está em execução e já chega outro". (GESTOR 2, 2015). A fala indica que as ações de socialização das propostas são realizadas por intermédio da 12a DIRED/SEEC e que falta o entendimento dos processos de implementação das propostas.

Além disso, percebemos que a escola, nos últimos anos, fez adesão a uma série de políticas, resultando assim, na falta de compreensão das finalidades, objetivos, metas e formas de funcionamento da proposta durante a implementação. Isso implica na descontinuidade das políticas públicas, precipuamente, daquelas políticas que se propõem a articular o Ensino Médio à Educação Profissional, às quais passam a ser compreendidas pelos gestores como ações fragmentadas e descontínuas em relação aos objetivos e metas estabelecidos inicialmente. (NASCIMENTO, 2012).

Tal fato é explicado por Dourado e Oliveira como um

[...] cenário complexo do quadro nacional e, ao mesmo tempo, permitem, com base em análise das políticas e programas governamentais, identificar a adoção histórica de uma determinada lógica político-pedagógica voltada 
para a ampliação das oportunidades educacionais, por meio da inclusão de etapas e modalidades educativas, sem fazer avançar, contudo, a adjetivação da qualidade pretendida. (DOURADO; OLIVEIRA, 2009, p. 202).

Os autores ressaltam que o processo de ampliação das oportunidades educacionais, neste caso, na articulação entre Ensino Médio e Educação Profissional, acontece sem avançar na proposta de expansão e qualidade pretendida. Com isso, no Brasil passa a ser cada vez mais recorrente a "[...] reivindicação de que as iniciativas governamentais no campo da educação sejam desenvolvidas na perspectiva de políticas públicas de Estado e não como programas de governo sem a continuidade e sustentabilidade das ações implementadas". (SIMÕES, 2011, p. 111). Sendo assim, os resultados da materialização de uma política não acontecem a curto prazo. Soma-se a isso, a ausência de consolidação e implementação de uma proposta educacional ${ }^{4}$ uniforme no cenário educacional do país, permitindo assim, a formulação e implementação de diferentes programas com objetivos e metas distintos.

Já na Escola Estadual Professor Abel Freire Coelho, dentre as políticas e programas mencionados, encontra-se o Programa Institucional de Bolsas de Iniciação à Docência (PIBID), Programa Institucional de Bolsas de Iniciação Científica (PIBIC), Espaço do Conhecimento, Curso Técnico de Nível Médio Integrado em Secretariado (Ensino Médio integrado à Educação Profissional), Programa Brasil Profissionalizado e PRONATEC. De acordo com o gestor entrevistado:

\begin{abstract}
Os programas são apresentados pela Secretaria de Educação (SEEC). Um dos motivos que influenciaram na adesão dos programas é pela quantidade de alunos que a escola começou a perder. Ao longo dos anos foi diminuindo a clientela da escola até ficar funcionando apenas dois turnos. Os alunos começaram a frequentar as escolas de Ensino Médio dos bairros que estavam sendo abertas. Além disso, boa parte dos alunos precisam trabalhar e deixavam a escola. Quando a proposta do Curso Técnico de Nível Médio Integrado em Secretariado foi apresentada a comunidade escolar abraçou como uma oportunidade para o funcionamento da escola voltar a funcionar nos três turnos. (GESTOR 4, 2015).
\end{abstract}

Reafirma-se, na fala do Gestor 4, que os programas são apresentados pela SEEC/RN. Dentre os motivos apontados que contribuíram para a adesão dos programas está o aumento, significativo, da taxa de evasão dos alunos, decorrentes, sobretudo, da necessidade de ingresso dos jovens no mercado de trabalho e das novas escolas de Ensino Médio abertas nos bairros. Nesse contexto, a implementação dessas políticas passa a ser interpretada como uma alternativa para superar as dificuldades específicas dessa etapa.

Dentre as políticas mencionadas, nos discursos dos dois gestores da Escola, evidenciou-se a adesão do Ensino Médio Integrado à Educação Profissional, realizada por meio do Curso Técnico de Nível Médio Integrado em Secretariado.

\footnotetext{
${ }^{4}$ Apesar da vigência do Plano Nacional de Educação (PNE/2014-2024) ainda não consolidou-se a implementação de uma proposta educacional no país que considere a gestão dos aspectos curriculares, pedagógicos e financeiro no Ensino Médio e Educação Profissional.
} 


\begin{abstract}
Em 2006, passou a funcionar 09 (nove) turmas do Curso Técnico de Nível Médio Integrado em Secretariado. O Curso estava iniciando e existia uma grande empolgação e expectativa da comunidade escolar. Eu cheguei a ministrar aulas no curso, então, peguei aula em todas as turmas do médio integrado, mas eu já cheguei sentindo as dificuldades do curso, pois eu entrei no segundo bimestre e eles não tinham tido nenhuma aula das disciplinas específicas. Daí em diante, fomos sempre percebendo essa dificuldade por parte do Estado. Para adesão a SEEC veio à escola e prometeu muita coisa em termos de equipamento, formação de professores e estrutura, mas até o final do curso só tinha chegado uma máquina de xerox e nada mais das coisas que haviam sido prometidas para 0 funcionamento do Curso. Nesse sentido, seria um atrativo para a escola trazer os alunos de volta, mas percebemos que foi ao contrário. A falta de professores das disciplinas específicas fez com que as turmas diminuíssem, pois os alunos ficavam sem aula. Muitos alunos fizeram assim quando chegavam no terceiro ano e percebiam as dificuldades do curso pediam para voltar para o "Ensino Médio Regular". A SEEC começou a aceitar, mas quando percebeu que estava tendo um número muito alto de mudanças ela bloqueou essa possibilidade. (GESTOR 3, 2015).
\end{abstract}

O acesso ao Curso permitia aos jovens uma possibilidade de formação profissional para atuar no mercado de trabalho. Nesse contexto, a Escola sobressaia-se das demais escolas públicas de Ensino Médio da cidade pela disposição de uma proposta político-pedagógica que articulava Ensino Médio à Educação Profissional. É interessante observarmos que, embora, a forma integrada seja apresentada como um diferencial pela escola para atrair mais alunos existe uma limitação em dois aspectos: primeiro, no que tange a oferta de 09 turmas de um único curso de formação, sendo necessário um amplo arranjo no mercado de trabalho local para absorver todos os profissionais formados para atuarem no campo de secretariado; segundo, a limitação das opções de escolhas dos jovens por outros campos de formação.

A implementação dessa proposta foi marcada por uma acentuada aceitação dos discentes, chegando a funcionar 09 (nove) turmas do Curso. Contudo, após a adesão e durante a implementação da proposta algumas dificuldades inviabilizaram as expectativas iniciais, pois a ausência de equipamento, falta de professores com formação específica e estruturas adequadas para viabilizar a proposta de integração do Ensino Médio à Educação Profissional, acarretando a conclusão de apenas 03 turmas em 2012. (GESTOR 3, 2015).

De modo resumido, percebemos que as políticas e programas implementados nas duas escolas servem de base para adesão e implementação de outras políticas. Neste caso, na adesão e implementação do Programa Brasil Profissionalizado podemos explicar utilizando o que diz Vicente: "no fluxo das soluções as pessoas que tem em comum áreas de atuação tentariam influenciar umas às outras, bem como uma grande quantidade de ideais seriam gerados e, de alguma forma e em algum momento são levadas em consideração". (2014, p. 39). Isso posto, podemos compreender que o processo de adesão ao Programa Brasil Profissionalizado foi mediado pelos embates e interesses dos sujeitos que integram as instituições 
envolvidas no processo e estão hierarquicamente acima dos gestores das Escolas, sem considerar os aspectos históricos envolvidos na trajetória da oferta de cursos nas instituições pesquisadas.

\section{CONSIDERAÇÕES FINAIS}

Neste artigo, discutiu-se a história da implementação e oferta da Educação Profissional pelo Programa Brasil Profissionalizado nas escolas estaduais, localizadas em Mossoró/RN. Na categoria políticas implementadas para articulação do Ensino Médio à Educação Profissional essas foram justificadas pela necessidade de superação das desigualdades sociais dos alunos que frequentam as escolas analisadas.

Em vista disso, as escolas são representadas como espaços favoráveis para concentração de políticas públicas que visam minimizar as desigualdades estruturais por serem espaços de construção e reconstrução das relações sociais e políticas.

$\mathrm{Na}$ análise dos gestores, identificamos um número expressivo de políticas implementadas no recorte temporal de 2007 a 2015, tendo como eixo central as ações para expandir e melhorar a qualidade da oferta do Ensino Médio e articular o Ensino Médio à Educação Profissional. No que compete ao favorecimento da expansão e qualidade da oferta do Ensino Médio destacam-se nas vozes dos gestores as seguintes iniciativas: Curso Técnico de Nível Médio Integrado em Secretariado (Ensino Médio integrado a Educação Profissional), Programa Brasil Profissionalizado e PRONATEC de forma acrítica e sem respaldo histórico do contexto, bem como sem observação da demanda e da oferta de cursos sem condições de absorção pelo mercado de trabalho.

De modo resumido, percebemos que as políticas e programas implementados nas duas escolas servem de base para adesão e implementação de outras políticas. Neste caso, na adesão e implementação do Programa Brasil Profissionalizado com os mesmos problemas enfrentados pelas demais políticas.

\section{REFERÊNCIAS}

BRAZIL, Maria do Carmo; FURTADO, Alessandra Cristina. Instituições escolares em Mato Grosso e Mato Grosso do Sul: primeiros apontamentos sobre a produção historiográfica nos Séculos XX e XXI. In: JOSÉ, Célio Juvenal Costa; MEL, Joaquim Pereira; FABIANO, Luiz Hermenegildo. (Org.). Fontes e métodos em história da educação. MS:Ed. UFGD, 2010. 350p.

CIAVATTA, Maria; SILVEIRA, Zuleide Simas. Celso Suckow da Fonseca. Recife: Fundação Joaquim Nabuco, 2010. 
DOURADO, Luiz Fernando; OLIVEIRA, João Ferreira. A Qualidade da Educação: perspectivas e desafios. Cadernos Cedes, Campinas, v. 29, n. 78, p. 201-215, maio/ago. 2009.

Luiz Fernandes. Ensino médio e educação profissional: para superar o dualismo estrutural. Retratos da Escola, Brasília, v. 5, n. 8, p. 7-9, jan./jun. 2011.

GERMANO, José Willington. O discurso político sobre a educação no Brasil autoritário. Cadernos Cedes, Campinas, vol. 28, n. 76, p. 313-332, set./dez. 2008.

HÖFLING, Eloisa de Mattos. Estado e Políticas (Públicas) Sociais. Cadernos Cedes, Campinas, v. 55, n. 21, p. 30-41, nov. 2001.

HOTZ, Celso. Estado e política educacional no Brasil (1979 A 1989). 2008. 200 f. Dissertação (Mestrado em Educação). Cascavel, PR, Universidade Estadual do Oeste do Paraná. Campus de Cascavel. Centro de Educação, Comunicação e Artes, 2008.

IANNI, Octavio. Estado e planejamento econômico no Brasil (1939-1970). 2. Ed. Rio de Janeiro: Civilização brasileira, 1971.

NASCIMENTO, Adriane Suely Rodrigues. Financiamento e Educação Profissional: análise do Programa Brasil Profissionalizado no Estado Pará. 2012. 175f. Dissertação (Mestrado em Educação) - Universidade Federal do Pará, Instituto de Ciências da Educação, Programa de Pós-Graduação em Educação, Belém, 2012.

PACHECO, Eliezer. Ensino médio e educação profissional: a ruptura com o dualismo estrutural. Revista Retratos da Escola, Brasília, v. 5, n. 8, p. 11-24, jan./jun. 2011.

SARMENTO, Maria Aurélia. A Escola Normal Primária de Mossoró (1922-1934): narrativas sobre a criação da primeira escola de formação de professores do interior do Rio Grande do Norte. 2013. 117 f. Dissertação (Mestrado em Educação) Universidade do Estado do Rio Grande do Norte, Faculdade de Educação, Programa de Pós-Graduação em Educação, Mossoró, 2013.

SIMÕES, Carlos Artexes. Políticas públicas do ensino médio: iniciativas governamentais e o Ensino Médio Inovador. Revista Retratos da Escola, Brasília, v. 5, n. 8, p. 1-190, jan./jun. 2011.

TOLEDO, Cézar de Alencar Arnaut; ANDRADE, Rodrigo Pinto. História da educação, instituições escolares, fontes e pesquisa em arquivos na região oeste do Paraná. Revista Linhas. Florianópolis, v. 15, n. 28, p. 175-199, jan.jun. 2014. 